\title{
Evaluación de efecto antibacteriano in vitro de la harina de látex de Carica pubenscens en Escherichia coli y Salmonella typhimurium
}

\section{In vitro antibacterial effect of Carica pubenscens latex meal on Escherichia coli and Salmonella typhimurium}

\author{
Darleny Tenorio Cruz ${ }^{1}$, Reiner Pedro Gabriel Reátegui Inga², Manuel Emilio Reátegui Inga ${ }^{3}$
}

\section{RESUMEN}

El objetivo de la presente investigación fue evaluar el efecto antibacteriano in vitro del látex de la papaya silvestre (Carica pubescens) en Escherichia coli y Salmonella typhimurium, para esto se colectaron muestras de heces de cuyes con presencia de diarreas de la granja PROALCUY. Los ensayos fueron realizados en el Laboratorio de Enfermedades Infecciosas y Parasitarias de Animales Domésticos de la Universidad Nacional Toribio Rodríguez de Mendoza de Amazonas (UNTRM), con tres tratamientos y un grupo testigo, cada una con 4 repeticiones, se usaron concentraciones de 0, 20, 40 y 60\% del látex de papaya silvestre. Los datos obtenidos fueron procesados por análisis de varianza (Diseño Completamente al Azar) y comparación de medidas Tukey con un nivel de significancia del 0,05. El efecto antibacteriano frente a Escherichia coli presento un tamaño de halo de $6 \mathrm{~mm}$ en todos los tratamientos mientras que en la Salmonella typhimurium 6, 6, 10,75 y 11,25 mm para las concentraciones $0,20,40$ y $60 \%$ de la harina de látex de papaya silvestre, respectivamente, evidenciando que el látex de papaya silvestre no tiene efecto antibacteriano frente a Salmonella typhimurium y Escherichia coli.

Palabras clave: Látex, papaya silvestre, antibacteriano.

\section{ABSTRACT}

The objetive of the present investigation was to evaluate the in vitro antibacterial effect of latex from wild papaya (Carica pubescens) in Escherichia coli and Salmonella typhimurium, for this we collected samples of guinea pig feces with the presence of diarrhea from the PROALCUY farm. The tests were carried out in the Laboratory of Infectiuos and Parasitic Diseases of Domestic Animals of the University Nacional Toribio Rodríguez de Mendoza de Amazonas (UNTRM), with three treatmenst and a control group, each with 4 repetitions, were used concentrations of $0,20,40$ and $60 \%$ of wild papaya latex. The data obtained were processed by analysis of varience (Completely Random Design) and comparison of Tukey meausares with a significance leve lof 0,05 . The antibacterial effect against Escherichia coli presented a halo size of $6 \mathrm{~mm}$ treatments, while in the Salmonella typhimurium $6,6,10,75$ and 11,25 for concetrations $0,20,40$ and $60 \%$ of the wild papaya latex meal, respectively, showing that the latex of wild papaya has no antibacterial effect against Salmonella typhimurium and Escherichia coli.

Keywords: Latex, wild papaya, antibacterial.

\footnotetext{
Bachiller de la Facultad de Ingeniería Zootecnista, Agronegocios y Biotecnología. Universidad Nacional Toribio Rodríguez de Mendoza de Amazonas. Correo electrónico:darlenytenoriocruz@gmail.com

${ }^{2}$ Docente de la Facultad de Ingeniería Zootecnista, Agronegocios y Biotecnología. Universidad Nacional Toribio Rodríguez de Mendoza de Amazonas. Maestro en Ciencias.Correo electrónico: reiner.reategui@untrm.edu.pe

${ }^{3}$ Docente de la Facultad de Ingeniería Forestal y Ambiental. Universidad Nacional de Jaén. Maestro en Ciencias. Correo electrónico: manuel.reategui@unj.edu.pe
} 


\section{INTRODUCCIÓN}

La salmonelosis es una enfermedad que se encuentra mucho en abundantes granjas de crianza de cuyes de nuestro país; las consecuencias clínicas ya son notorias (Chauca L. et al., 1997; Layme A. 2010 y Chero A. 2015) Su principal vía de transmisión es oral, pudiendo se transmitir tambien por la vía intrauterina y la leche (Zuñiga et al., 2001; Morales et al., 2007; Mattos etal., 2013).

La colibacilosis es una enfermedad que

ataca al tracto digestivo a nivel del intestino delgado; la bacteria que lo produce es la Escherichia coli en principal a los animales jóvenes y como síntoma principal el cuy va a estar erizado, con fiebre de 39,6 ${ }^{\circ} \mathrm{C}$, separado de los demás, inapetente, y puede haber diarrea profusa si no ha ocurrido la muerte, el intestino delgado muchas veces se encuentra distendido o relajado con presencia de líquido incoloro puede presentar nódulos a lo largo del intestino (Narváez, 2003).

Encontrando la alta incidencia y problemas que presentan estas bacterias en las explotaciones, se planteó llevar a cabo está investigación con la finalidad de tener una información para poder dar otras soluciones para poder suprimir o prevenir las diferentes enfermedades ocasionadas por dichas bacterias, el motivo también se dió a que no existen investigaciones suficientes sobre la utilización del látex de papaya silvestre (Carica pubescens) utilizado como product antibacteriano ante Escherichia coli y Salmonella typhimurium en la producción de cuyes, puesto que la mayoría de investigaciones se realiza en otras especies animales.

En la actual investigación sea tratado de la siguiente hipótesis: El látex in vitro de la papaya silvestre tendrá un efecto antibacteriano en Escherichia coli y Salmonella typhimurium en cuyes, de donde el objetivo general fue evaluar el efecto antibacteriano in vitro del látex de la papaya silvestre (LPS) en Escherichia coliy Salmonella typhimurium.

\section{MATERIALES Y MÉTODOS}

\section{Localización}

El siguiente trabajo de investigación se dio a cabo en el Laboratorio de Enfermedades Infecciosas y Parasitarias de Animales Domésticos perteneciente al Instituto de Investigación en Ganadería y Biotecnología - IGBI, de la Universidad Nacional Toribio Rodríguez de Mendoza de Amazonas, la que se encuentra en la provincia y distrito de Chachapoyas (Amazonas)

\section{Cepas bacterianas}

Las cepas bacterianas fueron adquiridas de las heces de los cuyes, de la granja PROALCUY, que presenten los respectivos sintomas de las enfermedades (colibacilosis y salmonelosis)

\section{Recolección de muestras de heces de cuyes}

Fueron identificados animales que presentaban síntomas de salmonelosis y colibacilosis en la granja.

Luego de dicha identificación se procedió al seguimiento de estos animales se seleccionó los galpones $\mathrm{H}, \mathrm{C}, \mathrm{B}, \mathrm{G}, \mathrm{F}$, posteriormente se llevó a cabo un estricto monitoreo de los animales con el fin de recolectar sus heces directamente del recto, las cuales fueron depositados en envases estériles de vidrio con un peso de $250 \mathrm{~g}$.

Las muestras colectadas fueron selladas y transportadas en una caja de tecnopor al laboratorio para su debida evaluación.

Siembra de las bacterias en medios de cultivos. Los demás procesos se realizaron apoyándome en los pasos descritos por Cruz et al., (2010), y con el apoyo del personal en microbiología que labora en el laboratorio de PROSAN.

\section{Enriquecimiento de muestras}

Con una pinza, se extrajo 5 gramos de heces de cada envase con las 0muestras de los diferentes galpones de cuyes.

Se colocó dicha cantidad en los envases de agua peptona o caldo peptona y agua de selenito o caldo selenito, dichos envases se encontraban etiquetados para cada una de las muestras.

Una vez colocados, se pasó a disolver bien para enriquecer mejor las muestras.

Al final se llevó a la estufa a incubar por un tiempo de 18 a 24 horas a una temperatura de $37^{\circ} \mathrm{C}$.

\section{Siembra de bacterias en medios de cultivo: Agar MacConkey y agar Salmonella Shiguella}

Colocamos los materiales a necesitar para la siembra en la cabina de seguridad y se coloca a luz ultravioleta (UV) por un tiempo aproximado de 10 minutos, en seguida se colocó las muestras enriquecidas en caldo peptona, caldo selenito en las placas con agar MC y SS en dicha cabina de seguridad.

Con la ayuda de un plumón indeleble se hizo el etiquetado correspondiente en cada placa de agar MC y SS y una regla se separó en dos partes tanto para caldo peptona y caldo selenito se lo realizo en cada una de las muestras.

Prendemos el mechero en la cabina y esterilizamos el asa bacteriológica en aro hasta formar un rojo vivo en el asa.

Se deja enfriar el asa para evitar la muerte de las bacterias al obtener la muestra, después se procedió a 
introducir el asa en el primer envase de muestra de heces enriquecida por varias veces, eliminamos la burbuja que se forma y se procedió a realizar la siembra en forma de zigzag o conocido como el método de estrías en las placas con agar MC y SS. Así mismo se procede a la siembra con cada una de las muestras enriquecidas y en cada placa de ambos agares ya mencionados, para cada muestra y cada placa de agar diferente se llevó a cabo la esterilización del asa bacteriológica.

En seguida se llevó a la incubación de las placas sembradas a la estufa a una temperatura de $37^{\circ} \mathrm{C}$ por un tiempo de 18 a 24 horas.

Por último, acabada la incubación se procedió a la identificación de la bacteria Salmonella typhimurium en el agar SS y el crecimiento de bacterias en agar MacConkey, después para la identificación de Escherichia coli se siguió la siembra en el medio de cultivo específico de agar EMB.

\section{Siembra de bacterias en medio de cultivo agar EMB}

Ponemos los materiales necesarios para dicho proceso en la cabina de seguridad y se puso luz UV por 10 minutos.

Trascurrido los 10 minutos con la ayuda de una regla y un plumón indeleble se separó en cuatro partes las placas de EMB 2 partes para caldo peptona y 2 partes para caldo selenito.

Después se examinó bien las colonias de bacterias formadas en la placa de agar $\mathrm{MC}$, se seleccionó una colonia de color rojo (caldo peptona) y otra de color blanco (caldo selenito).

Luego de las colonias seleccionadas se procedió a tomar la colonia de color rojo con la ayuda de un asa bacteriológica en aro esterilizada al rojo vivo con un mechero, se deja enfriar para evitar la muerte de bacterias al tomar la colonia y se llevó a cabo la siembra por el método de estrías o en zigzag en la placa con agar específico de EMB.

Se esterilizó el asa bacteriológica y de la misma manera se realizó la siembra de colonia de color blanco seleccionada en un placa con agar específico de EMB, para poder determinar cuál de las colonias seleccionadas con bacterias de Escherichia coli.

Por último, se colocó a incubar las placas con agar EMB sembradas en la estufa a $37^{\circ} \mathrm{C}$ de temperatura por 18 a 24 horas.

Transcurrido las horas de incubación se hizo la identificación de la bacteria, un color verde brillante nos confirmó la presencia de la bacteria de interés.

\section{Obtención de los discos de sensibilidad}

Se cogió el papel filtro y se procedió a cortar con un perforador de escritorio en forma circular con un diámetro de $6 \mathrm{~mm}$.

Después se colocó en un vaso de precipitación tapado con papel aluminio y se llevó a esterilizar en la incubadora a $37^{\circ} \mathrm{C}$ por 24 horas.

\section{Procedencia y obtención del látex de papaya silvestre}

Se obtuviron del distrito de Pomacochas me enviaron las papayas silvestres verdes al terminal terrestre de la cuidad de Chachapoyas.

Una vez que me entregaron el producto en el terminal terrestre, contraté un taxi que me trasladé a la UNTRM-A, específicamente al laboratorio de PROSAN donde se ejecutó la investigación.

En laboratorio se realizó el lavado y secado a 400 papayas silvestres verdes. Después se realizó cortes sagitales a c/u de las papayas silvestres para sacar el látex.

Se colocó el látex en una tabla de vidrio debidamente esterilizada donde se esparció todo el látex obtenido.

Por último, se llevó a colocar el látex extraído a la estufa a $150 \mathrm{C}^{\circ}$ por 24 para convertirle en harina.

\section{Preparación de los tratamientos}

Se coloca todos los materiales a utilizar en la cabina de seguridad y se desinfecta colocando a luz UV por 10 minutos, después colocamos nuestros insumos y empezamos a la preparación de los tratamientos. En esta investigación como insumos se utilizó la harina de látex de papaya silvestre (HLPS) y agua destilada esterilizada

Con apoyo de una pipeta se empezó a medir los insumos con las siguientes cantidades:

- T0 $=0 \%$ HLPS $(0 \mathrm{~g}$ de harina $+25 \mathrm{ml}$ de agua destilada)

- $\mathrm{T} 1=20 \%$ HLPS $(5 \mathrm{~g}$ de harina $+20 \mathrm{ml}$ de agua destilada)

- T2 $=40 \%$ HLPS ( $10 \mathrm{~g}$ de harina $+15 \mathrm{ml}$ de agua destilada)

- T3 $=60 \%$ HLPS $(15 \mathrm{~g}$ de harina $+10 \mathrm{ml}$ de agua destilada)

Después de colocadas las cantidades en los envases de vidrio respectivos a cada tratamiento se procede a mover las cantidades a través de movimientos circulares suaves.

\section{Evaluación del efecto antibacteriano del látex de papaya silvestre}

El proceso de esta etapa se llevó a cabo teniendo en cuenta a Cruz et al., (2010) y con las indicaciones de 
un biólogo que asistió de apoyo.

Se necesitó para la evaluación materiales estériles por lo que se colocó todos los materiales a utilizar para la siembra y evaluación de efecto antibacteriano del látex de papaya silvestre a la estufa a una temperatura de $150^{\circ} \mathrm{C}$ por una 1 hora.

\section{Evaluación del efecto antibacteriano de látex de papaya silvestre frente a Escherichia Coli}

Se inicio el procedimiento colocando los materiales e insumos a utilizar en la cabina de seguridad a luz UV por 10 minutos.

Después para realizar la siembra y evaluar el efecto antibacteriano de la HLPS se llevó a cabo la suspensión con la bacteria de Escherichia coli colocando $1 \mathrm{ml}$ de agua destilada esterilizada en un tubo de ensayo.

Con la ayuda del mechero se esterilizó un asa bacteriológica en aro a rojo vivo, se enfrió y se cogió una cantidad de bacterias de Escherichia coli del agar EMB y se le agregó al tubo que contenía el agua destilada esterilizada, después se movió bien con el asa bacteriológica y elaboramos nuestra suspensión bacteriana de E coli.

En el tubo con la suspensión bacteriana se introdujo un hisopo con el que también movimos para obtener una buena muestra y dicho hisopo se exprime bien en las paredes del tubo.

Una vez exprimido, sembramos con el hisopo inclinado en las placas con agar Müller- Hinton en diferentes direcciones realizando una vuelta entera a los bordes del interior de la placa para conseguir un mejor crecimiento de la bacteria en toda la superficie del agar y tapamos la placa.

De igual manera con el mismo hisopo para cada siembra en cada una de las placas con agar Müller Hinton se metió en el tubo con la suspensión bacteriana, se exprime bien y se llevó a cabo la siembra con los mismos pasos. Elaboramos 4 placas con agar Müller- Hinton sembradas con bacterias de Escherichia coli para llevar a cabo la evaluación de los 4 tratamientos respectivos.

Con la ayuda de un plumón indeleble y regla se distribuyó cada una de las 4 placas sembradas en 4 partes iguales, las que se rotuló el nombre de la bacteria, tipo de tratamiento y número de repeticiones, éste último en cada uno de los cuadrantes. Luego se insrtó los discos, de la siguienta manera:

\section{$\checkmark$ Inserción de los discos de sensibilidad}

Se trabajo en la cabina de seguridad, en el envase de cada tratamiento, se introdujo un disco de sensibilidad con el apoyo de una pinza, el cual se humedeció en el primer tratamiento que fue el T0: que contenía agua destilada esterilizada, se quitó del envase y se colocó en la primera placa y en el primer cuadrante.

Del mismo modo se llevó a cabo la inserción de todos los discos del primer tratamiento, a los cuales fueron 4 discos, 1 disco para cada repetición.

En las demás inserciones de los discos de sensibilidad se realizó el mismo método y con su respectivo tratamiento.

Por último, terminada la inserción de los discos a cada una de las 4 placas con su correspondiente tratamiento, se llevó a incubación en la estufa auna temperatura de $37^{\circ} \mathrm{C}$ por 18 a 24 horas.

Terminado el tiempo de incubación se llevó a cabo la respectiva lectura del efecto antibacteriano del látex de papaya silvestre en sus 4 diferentes porcentajes de concentración.

Evaluación del efecto antibacteriano del látex de papaya silvestre frente a Salmonella Typhimurium

Se inicio el procedimiento colocando los materiales e insumos a utilizar en la cabina de seguridad a luz UV por 10 minutos.

Después para realizar la siembra y evaluar el efecto antibacteriano del látex de papaya silvestre se llevó a cabo la suspensión con la bacteria de Salmonella typhimurium colocando $1 \mathrm{ml}$ de agua destilada esterilizada en un tubo de ensayo.

Con la ayuda del mechero se esterilizó un asa bacteriológica en aro a rojo vivo, se enfrió y se cogió una cantidad de bacterias de Salmonella typhimurium del agar SS y se le agregó al tubo que contenía el agua destilada esterilizada, después se movió bien con el asa bacteriológica y elaboramos nuestra suspensión bacteriana de Salmonella typhimurium.

En el tubo con la suspensión bacteriana se introdujo un hisopo con el que también movimos para obtener una buena muestra y dicho hisopo se exprime bien en las paredes del tubo.

Una vez exprimido, sembramos con el hisopo inclinado en las placas con agar Müller- Hinton en diferentes direcciones realizando una vuelta entera a los bordes del interior de la placa para conseguir un mejor crecimiento de la bacteria en toda la superficie del agar y tapamos la placa.

De igual manera con el mismo hisopo para cada siembra en cada una de las placas con agar Müller Hinton se metió en el tubo con la suspensión bacteriana, se exprime bien y se llevó a cabo la siembra con los mismos pasos. Elaboramos 4 placas con agar Müller- Hinton sembradas con bacterias de Salmonella typhimurium para llevar a cabo la evaluación de los 4 tratamientos respectivos.

Con la ayuda de un plumón indeleble y regla se 
distribuyó cada una de las 4 placas sembradas en 4 partes iguales, las que se rotuló el nombre de la bacteria, tipo de tratamiento y número de repeticiones, éste último en cada uno de los cuadrantes. Luego se insrtó los discos, de la siguienta manera:

\section{$\checkmark$ Inserción de los discos de sensibilidad}

Se trabajo en la cabina de seguridad, en el envase de cada tratamiento, se introdujo un disco de sensibilidad con el apoyo de una pinza, el cual se humedeció en el primer tratamiento que fue el T0: que contenía agua destilada esterilizada, se quitó del envase y se colocó en la primera placa y en el primer cuadrante.

Del mismo modo se llevó a cabo la inserción de todos los discos del primer tratamiento, a los cuales fueron 4 discos, 1 disco para cada repetición.

En las demás inserciones de los discos de sensibilidad se realizó el mismo método y con surespectivo tratamiento.

Terminada la inserción de los discos a cada una de las 4 placas con su correspondiente tratamiento, se llevó a incubación en la estufa a una temperatura de $37^{\circ} \mathrm{C}$ por 18 a 24 horas.

Terminado el tiempo de incubación se llevó a cabo la respectiva lectura del efecto antibacteriano del látex de papaya silvestre en sus 4 diferentesporcentajes de concentración

\section{RESULTADOS}

Tabla 1

Tamaño del halo ( $\mathrm{mm}$ ) por efecto del látex de papaya sobre Salmonella typhimurium

\begin{tabular}{|c|c|}
\hline Tratamiento & $\begin{array}{c}\text { Diámetro del halo } \\
(\mathbf{m m})^{*}\end{array}$ \\
\hline $0 \% \mathrm{EA}$ & $6 \mathrm{C}$ \\
\hline $20 \% \mathrm{EA}$ & $6 \mathrm{BC}$ \\
\hline $40 \% \mathrm{EA}$ & $10,75 \mathrm{AB}$ \\
\hline $60 \% \mathrm{EA}$ & $11,25 \mathrm{~A}$ \\
\hline
\end{tabular}

*Diferentes letras en una fila indica diferencia estadística $(\mathrm{p}<0,05)$

En la tabla 1, se puede observar que el promedio del tamaño del halo de inhibición en los tratamientos $0 \%$ y $20 \%$ fue de $6 \mathrm{~mm}$ son iguales, lo que quiere decir que no hay crecimiento del halo, en cambio en el tratamiento al $40 \%$ es $10,75 \mathrm{~mm}$ superior y el $60 \%$ $11,25 \mathrm{~mm}$, lo cual indica que solo los dos últimos tratamientos presentaron crecimiento del halo
Tabla 2

Tamaño del halo ( $\mathrm{mm}$ ) por efecto del látex de papaya sobre Escherichia coli

\begin{tabular}{|c|c|}
\hline Tratamiento & $\begin{array}{c}\text { Diámetro del halo } \\
(\mathbf{m m})^{*}\end{array}$ \\
\hline $0 \% \mathrm{EA}$ & $6 \mathrm{~A}$ \\
\hline $20 \% \mathrm{EA}$ & $6 \mathrm{~A}$ \\
\hline $40 \% \mathrm{EA}$ & $6 \mathrm{~A}$ \\
\hline $60 \% \mathrm{EA}$ & $6 \mathrm{~A}$ \\
\hline
\end{tabular}

*Diferentes letras en una fila indica diferencia estadística $(\mathrm{p}<0,05)$

En la tabla 2, el promedio del tamaño del halo de inhibición de los tratamientos evaluados fue de 6 $\mathrm{mm}$, lo que evidencia que en la presente investigación el efecto antibacteriano del látex de papaya silvestre ante Escherichia coli es nulo, ya que no se encontró ningún crecimiento del halo, lo que quiere decir que los $6 \mathrm{~mm}$ es el tamaño del disco de sensibilidad.

\section{DISCUSIÓN}

Los resultados muestran que el látex de papaya silvestre (Carica pubescens) muestra un efecto antibacteriano en concentraciones de 40 y $60 \%$ frente a la bacteria de Salmonella typhimurium con un crecimiento del halo 10,75 y $11,25 \mathrm{~mm}$ lo que quiere decir que si hay un crecimiento del halo, lo que se puede corroborar que la siguiente investigación del efecto antibacteriano del látex de papaya silvestre frente a Salmonella typhimurium es nulo en los tratamientos $0 \%$ y $20 \%$ ya que no hay crecimiento del halo.

Sin embargo, al utilizarlo como antibacteriano frente Escherichia coli de los cuyes, en efecto los resultados de crecimiento del halo de inhibición se tiene $6 \mathrm{~mm}$ en todos los tratamientos acabo incluyendo los $6 \mathrm{~mm}$ del disco de sensibilidad, lo que representa que una lectura de $6 \mathrm{~mm}$ indica que no hay zona de inhibición. Guzmán (1984) nos explican que para la toma de medidas de la inhibición se lleva acabo incluyendo los $6 \mathrm{~mm}$ del disco de sensibilidad, lo que representa que una lectura de $6 \mathrm{~mm}$ indica que no hay zona de inhibición.

La resistencia encontrada en esta investigación de las bacterias Escherichia coli y Salmonella typhimurium frente al látex de papaya silvestre se debe a que exista resistencia antimicrobiotica como indica Harkness y Morris (1995); La diferencia en las cepas resistentes entre estreptomicina, aminoglucósidos y gentamicina, se consigue explicar por consiguiente que las enzimas bacterianas empleadas que las inactivan pueden ser específicas para cada uno de ellos. 
Los tamaños por halos que se obtuvieron para las 2 bacterias de 6 a $11,75 \mathrm{~mm}$ la interpretación de susceptibilidad es resistencia como indica. (Reyes et al., 2005) explican que la susceptibilidad del microorganismo en prueba se refiere con el tamaño de la zona de inhibición en milímetros. En esta investigación se obtuvo parámetros de zona de inhibición de 6 a 11,75 mm y la interpretación de las bacterias fueron resistentes frente al látex como indica (Lopez-Malo et al., 2005); Estos microorganismos se designan susceptibles cuando el diámetro de la zona es mayor a 30-35 Escherichia coli, no se notó ningún crecimiento visible en los discos de sensibilidad; para comprender Bernal y Guzmán (1984) nos explican que para la toma de medidas de la inhibición se lleva $\mathrm{mm}$, intermedios cuando el diámetro de la zona varía entre 20 y $30 \mathrm{~mm}$, y resistentes cuando el diámetro de la zona es menor a $15-20 \mathrm{~mm}$.

Por lo predispuesto en este párrafo, se puede definir que nuestros resultados no se encuentran en los rangos establecidos y se puede constatar que las bacterias estudiadas son resistentes ante el látex de papaya silvestre ya que hay crecimiento del halo.

\section{CONCLUSIÓN}

La harina de látex de papaya silvestre no tiene efecto antibacteriano sobre la Escherichia coli y Salmonella typhimurium.

\section{REFERENCIAS BIBLIOGRÁFICAS}

Bernal, M. y Guzmán, M. (1984). El antibiograma de discos. Normalización de la técnica de Kirby -Bauer. Biomédica 4 (3 y 4), 112-121.

Chauca L. 1997. Producción de Cuyes (Cavia porcellus). Organización de la Naciones Unidas. Para la Agricultura y la Alimentación de la FAO. Instituto Nacional de Investigaciones Agraria INIA. Roma 77 p.

Chero A. 2015. Identificación molecular de Salmonella typhimurium y entiritidis en cobayos reproductoras primerizas clínicame nte sanas. Tesis Médico Veterinario. Lima: Facultad de Medicina Veterinaria, Universid ad Nacional Mayor de San Marcos. 54 p

Harkenns J.Jenkins J (eds). Exotic animal formulary: a supplement to $A A H A^{\prime}$ practitioner guides to exotic animal medicine. Colorado: American Animal Hospital Association p 3746.
Layme A. 2010. Frecuencia de lesiones anatomopa tológicas en cobayos con diagnostico bacteriológico de Salmonella sp remitidos al laboratorio de histología, embriología y patología veterinaria de la FMV- UNMSM durante el periodo 2001-2007. Tesis Médico Veterinario. Lima: Facultad de Medicina Veterinaria, Universidad Nacional Mayor de San Marcos. 54 p

López-Malo, A., Palou, E., Parish, M. y Davidson, P. (2005). Methods for activity assay and evaluation of results. En P. M. Davidson, J., Sofos, y A Branen.antimicrobials in Food (3a edición, capitulo 21, pags.659-680). Boca ratón: CRC Press, Taylor \& Francis Group.

Mattos J. Palacios G. Glorio P, Morales S. 2013. Efecto de la muña (Satureja parvifolia) como aditivo no nutricional en la estimulación de Lactobacillus sp., y control de Salmonella Typhimurium en cuyes de carneCientifica. 10 (2):123- 134.

Morales S, Mattos J, Calle S. 2007. Efecto de la muña (Satureja parvifolia) en La dinámica de la infección de Salmonella entérica en cobayos. Reunión de la Asociación Latinoamericana de Producción de Animales, Cuzco - Perú.

Narváez, H. 2003. Explotación técnica de cuyes Manual de asistencia técnica N.-5 San Juan de Pasto Edición Comité editorial Regional Cinco. Bogotá DC. 35-36 Pgs. 